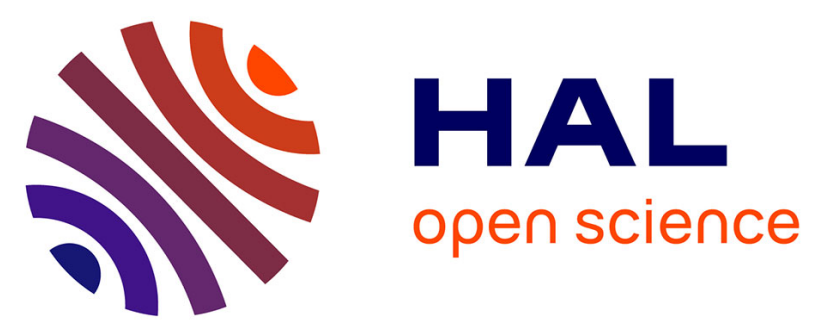

\title{
Patients with metastatic melanoma receiving anticancer drugs: changes in overall survival, 2010-2017
}

Florence Poizeau, Sandrine Kerbrat, André Happe, Caroline Rault, Erwan

Drezen, Frédéric Balusson, Philippe Tuppin, Bernard Guillot, Anne Thuret, Lise Boussemart, et al.

\section{To cite this version:}

Florence Poizeau, Sandrine Kerbrat, André Happe, Caroline Rault, Erwan Drezen, et al.. Patients with metastatic melanoma receiving anticancer drugs: changes in overall survival, 2010-2017. Journal of Investigative Dermatology, 2021, 141 (4), pp.830-839.e3. 10.1016/j.jid.2020.07.038 . hal-02978211

\section{HAL Id: hal-02978211 \\ https://hal.science/hal-02978211}

Submitted on 11 Dec 2020

HAL is a multi-disciplinary open access archive for the deposit and dissemination of scientific research documents, whether they are published or not. The documents may come from teaching and research institutions in France or abroad, or from public or private research centers.
L'archive ouverte pluridisciplinaire HAL, est destinée au dépôt et à la diffusion de documents scientifiques de niveau recherche, publiés ou non, émanant des établissements d'enseignement et de recherche français ou étrangers, des laboratoires publics ou privés. 


\section{Patients with metastatic melanoma receiving anticancer drugs: changes in overall survival, 2010-2017.}

Short title: Metastatic melanoma in France: 2010-2017

Florence Poizeau ${ }^{1,2,3}$, Sandrine Kerbrat ${ }^{1,2}$, André Happe ${ }^{1,2}$, Caroline Rault ${ }^{1,2}$, Erwan Drezen $^{1,2}$, Frédéric Balusson ${ }^{1}$, Philippe Tuppin ${ }^{4}$, Bernard Guillot ${ }^{5}$, Anne Thuret ${ }^{6}$, Lise Boussemart $^{3,7}$, Monica Dinulescu ${ }^{3}$, Marc Pracht ${ }^{8}$, Thierry Lesimple ${ }^{8}$, Catherine Droitcourt ${ }^{1,2}$, ${ }^{3}$, Emmanuel Oger ${ }^{1,2}$, Alain Dupuy ${ }^{1,2,3}$

${ }^{1}$ Univ Rennes, CHU Rennes, EA 7449 (Pharmacoepidemiology and Health Services Research) REPERES, F 3504, Rennes, France

${ }^{2}$ PEPS Research Consortium (Pharmacoepidemiology for Health Product Safety), Rennes, France

${ }^{3}$ Department of Dermatology, CHU Rennes, Rennes, France

${ }^{4}$ Department of Public Health Research, CNAM, Paris, France

${ }^{5}$ Department of Dermatology, CHU Montpellier, France

${ }^{6}$ Non-communicable diseases and Trauma Division, Santé Publique France, the French Public Health Agency, Saint Maurice, France

${ }^{7}$ Rennes 1 University, CNRS, IGDR, UMR 6290, Rennes, France

${ }^{8}$ Department of Medical Oncology, Centre Eugène Marquis, Rennes, France

Corresponding author: Alain Dupuy, $\mathrm{MD}, \mathrm{PhD}$

Department of Dermatology, CHU Rennes, 2 rue Henri le Guilloux 35000 Rennes, France, Tel: + 332 992843 68, Fax: + 33299284100

Mailto: alain.dupuy@ chu-rennes.fr.

Twitter handle: EReperes

\section{ORCID numbers:}

Florence Poizeau 0000-0002-0754-361X

Sandrine Kerbrat 0000-0003-4119-203X

André Happe 0000-0001-9487-1533

Caroline Rault 0000-0001-9719-0653

Erwan Drezen 0000-0002-4054-5668

Frédéric Balusson 0000-0001-6684-1361

Philippe Tuppin 0000-0001-5698-9215

Bernard Guillot 0000-0001-6139-4136

Anne Thuret 0000-0002-9637-3084

Lise Boussemart 0000-0002-6895-0139

Monica Dinulescu 0000-0002-3950-4340

Marc Pracht 0000-0001-8110-0780

Thierry Lesimple 0000-0002-1360-5135

Catherine Droitcourt 0000-0001-6714-6643

Emmanuel Oger 0000-0001-9837-2977

Alain Dupuy 0000-0003-3212-7455

Word count: 3451 words 


\section{List of abbreviations:}

95\%CI: 95\% confidence interval

HR: hazard ratio

ICD-10: international classification of diseases 10th revision

ICI: immune checkpoint inhibitors

OS: overall survival

PD-1: programmed cell death 1

RCT: randomized controlled trial

SNDS : Système National des Données de Santé 


\section{ABSTRACT}

Immune checkpoint inhibitors (ICI) and targeted therapies have profoundly altered the management of several cancers over the past decade. Metastatic melanoma has been at the forefront of these changes.

We provide here a nationwide overview and an assessment of changes in survival in France.

We included 10,936 patients receiving a systemic treatment for metastatic cutaneous melanoma between 2010 and 2017 using the French national health insurance database (SNDS, ex-SNIIRAM). Over the study period, there was a doubling of the number of new patients receiving a systemic treatment. Cytotoxic chemotherapy was progressively replaced by targeted therapy and ICI. Patients having initiated a first-line treatment since June 2015 gained $46 \%$ OS compared to those initiating treatment before 2012. 24-month OS rose from $21 \%$ to $44 \%$.

We provide real-world evidence for the improvement of OS in the past decade among patients with metastatic melanoma. Although the characteristics of the patients treated can vary across periods, this type of exhaustive real-world data provides evidence from broader populations than those included in clinical trials. 


\section{INTRODUCTION}

Metastatic melanoma has been at the forefront of the recent changes in oncology. For almost 40 years, cytotoxic chemotherapy used in metastatic melanoma had been associated with a median survival of less than 12 months (Balch et al. 2009). The emergence of new anticancer drugs over the last 10 years has profoundly changed treatment strategies, since each new treatment has demonstrated gains in survival over reference therapy in randomized controlled trials (RCTs) (Eggermont and Robert 2011; Ugurel et al. 2017). Novel therapeutic approaches have included immune checkpoint inhibitors (ICIs) and targeted therapies. A first wave of new anticancer drugs started in 2011 with the anti-CTLA-4 drug ipilimumab and BRAF inhibitors. Since 2015, agents targeting programmed cell death 1 (PD-1), and BRAF combined with MEK inhibitors have become the new standards.

The extent to which these changes have translated into an improvement in survival in the real world remains to be further investigated. We used the French insurance database to identify all patients who received a systemic treatment for metastatic cutaneous melanoma between 2010 and 2017 in France. Our objectives were to describe changes in anticancer drug use and to analyze the impact on overall survival over the study period. 


\section{RESULTS}

\section{Anticancer drugs used for metastatic melanoma: 2010-2017}

Every patient beginning a first-line treatment in France for metastatic cutaneous melanoma was included. The numbers of new patients per trimester between January 2010 and December 2017 are presented in Figure 1. The number of patients initiating an anticancer drug for melanoma more than doubled over the study period, from 910 in 2010 to 1890 patients in 2017 .

Drastic changes in therapeutic modalities were observed whenever a novel drug became available (Figure 1), leading to very distinct profiles for our 4 cohorts. Cytotoxic chemotherapy was the only therapeutic option in cohort 1 , and this was almost entirely replaced by novel therapies in the following cohorts. Vemurafenib, a BRAF inhibitor, became available from the starting date of cohort 2 . Cohort 3 had access to ipilimumab as a first-line additional option. The hallmarks of cohort 4 were the availability of anti-PD-1 antibodies as first-line treatment and the combination of MEK and BRAF inhibitors for targeted therapies. Therefore, the 4 cohorts reflected time periods with very distinct categories of first-line treatment options (Figure 1c). Age, sex and comorbidities among the advanced melanoma patients were fairly stable across the cohorts (Table 1).

\section{Changes over time in patient care trajectories}

For each cohort, a visual representation of vital status and treatment lines at 6 and 12 months after a first anticancer drug had been initiated is presented in Figure 2. This descriptive data show how the variety of available drugs impacts care trajectories, not only for first-line treatments but also for subsequent treatment lines. 


\section{Changes over time in overall survival for metastatic melanoma patients}

Overall survival in cohorts 2, 3, and 4 was compared to cohort 1. Crude hazard ratios (HR) and $95 \%$ confidence intervals $(95 \% \mathrm{CI})$ were 0.93 [0.87-1.00], 0.69 [0.64-0.74], and 0.54 [0.50-0.57] respectively. After adjustment on age, sex, comorbidities (congestive heart failure, cerebrovascular disease, chronic pulmonary disease, renal disease), number and location of metastatic sites (lymph node, lung, liver, brain, bone), surgical resection of distant metastases and radiotherapy in the 12 months before initiation of the first-line treatment, $\mathrm{HR}$ [95\% CI] were $0.92[0.85-0.98], 0.72[0.67-0.77]$ and 0.56 [0.52-0.60]. Median, 1-year and 2-year overall survival results in each cohort are provided in Table 2, and survival curves are presented in Figure 3. The estimated effects of patient characteristics, number and location of metastatic sites, prior surgical resection and radiotherapy on overall survival are shown in Supplementary Table S1.

\section{Overall survival according to the first-line treatment received}

Overall survival was estimated for the two most widely prescribed first-line treatment categories within each cohort (Figure 4, Supplementary Table S2). The best survival was obtained for patients from cohort 4 treated with anti-PD-1 antibodies as first-line treatment ( $\mathrm{n}=2605$; median overall survival: 22.5 months, 95\%CI [19.2-25.7], 24-month overall survival: $48.4 \%$, 95\%CI [45.7\%-51.1\%]). Patients from cohort 3 receiving ipilimumab as a first-line treatment $(\mathrm{n}=832)$ had a median overall survival of 16.3 months, 95\%CI [13.6-18.8], and a 24-month overall survival of $42.2 \%, 95 \% \mathrm{CI}$ [38.8\%-45.5\%]. Targeted therapies (which shifted over time from BRAF inhibitor monotherapy to a combination of BRAF and MEK inhibitors) provided increasingly better results according to the time period (median overall survival from 10.6 months [9.5-11.8] in cohort 2 to 15.9 months [14.9-17.7] in cohort 4 ; 24month overall survival from $24.4 \%[21.2-27.5]$ to $39.6 \%$ [36.4-42.8]). 


\section{DISCUSSION}

From a large overview at French nationwide level, we report an improvement in overall survival among patients with metastatic cutaneous melanoma treated with anticancer drugs over the 2010-2017 period. Two-year overall survival rose from 21 to $44 \%$.

The use of routinely collected data has the potential to provide important information in a public health perspective (Booth et al. 2019). The French national health insurance system covers $98.8 \%$ of the population living in France and registers all deaths (Bezin et al. 2017; Tuppin et al. 2017). It enabled us to identify and follow all French patients with metastatic melanoma without attrition bias. Due to the characteristics of the French health insurance system and the homogeneous public and private hospital coding rules, we can confidently say that every patient treated with systemic anticancer drugs for metastatic melanoma was identified. Patients for whom the metastatic disease was left untreated or was treated exclusively with surgery or radiotherapy were outside the scope of this study (Supplementary Table S3).

Other real-world approaches in melanoma have been developed in France: MelBase is a multicentre bioclinical cohort following more than 1300 patients with advanced melanoma since 2013 (Kandel et al. 2018; Tétu et al. 2019); the RIC-Mel registry includes all-stage melanomas, with a minority of metastatic patients (Bocquet-Tremoureux et al. 2019). A vast amount of real-world data from other countries provided information about the effectiveness and safety of novel therapies in different populations (Cowey et al. 2019; Forschner et al. 2016; Luke et al. 2019; Mangana et al. 2017; Moser et al. 2020; Polkowska et al. 2017; Tarhini et al. 2019; Whitman et al. 2019). However, these studies explore selected population, and therefore have limited generalizability. Little exhaustive data from nationwide population-based registries or databases are available (Donia et al. 2019; Jochems et al. 2017). Registries in the Netherlands and Denmark have addressed several questions on metastatic 
melanoma management and provided survival results close to ours (Donia et al. 2019; Jochems et al. 2017). Studies by the Dutch registry focused on a limited time frame, from 2012 to 2015, and on two novel therapied of that period: vemurafenib and ipilimumab (Jochems et al. 2018; Schouwenburg et al. 2018). The Danish database enabled patients, treatments and outcomes to be described in $2012(n=83), 2014(n=129)$ and $2016(n=115)$ (Donia et al. 2019). Data from a larger population, and over the whole 2010-2017 period, were thus required to study all available immunotherapies and targeted therapies. We here provide this large overview of therapeutic changes and their impact on overall survival, according to the period and the first-line treatment received.

The number of patients starting a first-line anticancer drug for metastatic melanoma over the study period increased twofold between 2010 and 2017. The incidence of melanoma has been steadily increasing by 2.4 and $3.4 \%$ a year in men and women respectively over the past decade (Defossez G, Le Guyader-Peyrou S, Uhry Z, Grosclaude P, Colonna M, Dantony E). Under the hypothesis that this increase fuels the metastatic stage in the same proportion, this increase in incidence explains $22 \%$ of the observed increase in newly-treated metastatic melanoma patients. Our data on comorbidities and metastasis profiles do not argue for a reservoir of patients who today would be treated with systemic anticancer drugs whereas they would have been left untreated in the years 2010-2011. Over the study period, we observed an increase in the proportion of patients starting a systemic anticancer drug within one year after a lymphadenectomy. This suggests that patients are now treated earlier in the metastatic course. Roughly, the availability of efficacious treatments could lead to their use for asymptomatic patients presenting radiological evidence of metastasis, while in earlier periods, when only underperforming chemotherapy was available, the treatment was not initiated until the metastases had become symptomatic. 
A comparison of overall survival across our 4 cohorts evidenced a striking improvement over the study period. This improvement runs parallel to the availability of more and more efficacious anticancer drugs, for which clinical benefits have been demonstrated in many published RCTs (Ugurel et al. 2017). Our data on drug use and therapeutic sequences evidence the dramatic changes that any clinician treating patients with metastatic melanoma has experienced over recent years. It is important to recall, however, that observational studies are prone to biases, most importantly selection and indication bias (D'Agostino and D'Agostino 2007). Most of the changes in therapeutic management are direct consequences of better therapeutic efficacy (and often better tolerance) of new drugs. But, because the decision to treat or not to treat a patient could differ according to the therapies available, and since we compared survival across treated patients, the improved survival across the cohorts is not only attributable to the improved effectiveness of novel therapies. Concrete examples of clinical situations are presented in the Box. In a situation of such rapid and drastic changes in treatment strategies, propensity score would be of little help (Stukel et al. 2007). We can rather consider that the period is the best global proxy for known and unknown confounders, and we used the period as a relevant and meaningful factor to compare the strategies. In another study involving 837 Danish patients, the same approach of comparing periods demonstrated a similar improvement in survival (Donia et al. 2019).

We report survival according to treatment category within each cohort. As expected, for most treatments, real-world survival in our study was lower than its counterparts reported in RCTs (Ugurel et al. 2017). Excluding patients with brain metastases or severe comorbidities from most RCTs leads to a lack of comparability between trial participants and non-participants (Donia et al. 2019; Elting et al. 2006; Sanoff et al. 2016). In addition, the higher toxicity of treatments in a real-world setting alters drug regimens and could lead to reduced effectiveness (Fraser et al. 2011; Prasad et al. 2014). Only patients treated with first-line ipilimumab in our 
study exhibited better survival than those reported in RCTs (Ugurel et al. 2017). Anti-PD-1 antibodies as a second-line therapy ( $34.7 \%$ of patients in our study), which were not available for earlier ipilimumab users, could explain these differences. Among patients treated with targeted therapy as the first line, improved survival across cohorts 2 to 4 was observed, a phenomenon probably due to the availability of different second-line treatments, and also to the arrival of MEK inhibitors combined with BRAF inhibitors, this combination being more efficacious and better tolerated than monotherapy with BRAF inhibitors (Flaherty et al. 2012; Larkin et al. 2014; Long et al. 2014; Robert et al. 2015). We did not directly compare survival rates of patients receiving ICIs vs. targeted therapy, since the latter is only offered to patients with $B R A F$-mutated melanoma, which could in itself entail a poorer prognosis (Bucheit et al. 2013; Long et al. 2011; Thomas et al. 2015). Interestingly, distinct shapes of survival curves were observed between patients receiving a targeted therapy ( $B R A F$-mutated melanoma) or an ICI (mostly wild-type melanoma) as first-line treatment. The survival curves crossed at 8 and 9 months for cohorts 3 and 4 respectively. This crossing point had already been identified in RCTs (Ugurel et al. 2017). This suggests a more rapid effect of targeted therapy, and then longer remissions obtained with ICIs and/or an intrinsically poorer prognosis for $B R A F$ mutated melanoma (Luke et al. 2019; Moser et al. 2019; Schilling et al. 2019).

Exhaustiveness at nationwide level and the absence of attrition bias are among the strengths of our study, as is the quality of the information enabling the reconstruction of individual care trajectories. Beyond the limitations inherent in observational studies mentioned above, some potential weaknesses should be discussed. First, the identification of chemotherapy is based on ICD-10 Z51.1 coding and we cannot exclude the possibility that a small minority of miscoded Z51.1 hospitalisations were contemporaneous to participation in a clinical trial. Some first-line treatments referred to as "chemotherapy" in cohort 4 were dispensed by investigative centres where cytotoxic chemotherapy as the first-line approach had been 
abandoned. This is why the Z51.1-based category has been labeled "chemotherapy \& other". Although we have no means to estimate the magnitude of this potential misclassification, the coding rules and the evolution of the category over the study period argue for a very large majority of true cytotoxic chemotherapies. Second, with the exception for the abovementioned situation, participation in a clinical trial implies no billing to the National Health Insurance, this time period being invisible in our study. Therefore, some so-called first-line treatments may have actually been second-line treatments following participation in a clinical trial. Third, we had no individual clinical data outside the discharge codes, and important information such as the $B R A F$ genotype was not available. According to a report from the French genotyping platforms (INCa 2013), BRAF mutation is presently identified in $37.5 \%$ of melanomas, a proportion close to the $33.0 \%$ of patients receiving a targeted therapy as the first-line treatment in cohorts 2 to 4 .

We here provide an overview of the treatment of metastatic melanoma within a key timeframe that covered major changes in the therapeutic landscape. Real-world studies are complementary to randomized controlled trials for medical evidence. We believe that realworld overviews are helpful for clinicians and patients when considering long-term prognoses and treatment decisions, especially for patients who are under-represented in clinical trials. They are also useful for clinicians to evaluate their practice at population level and for health authorities in an economic perspective. Despite the achievements in improving survival for metastatic melanoma patients, a majority of patients still die in the short term. In our study, even for cohort $4,56 \%$ of patients died within 24 months after the initiation of an anticancer drug for metastatic melanoma. Further progress towards curing melanoma is clearly needed. Current hope lies in adjuvant therapy for resected stage III melanoma. Both ICIs and the combination of BRAF and MEK inhibitors have proven efficacy for recurrence-free survival in large RCTs (Eggermont et al. 2018; Eggermont et al. 2016; Hauschild et al. 2018; Long et 


\section{Joumal Pre-proof}

al. 2017; Weber et al. 2017). Large-scale real-world data will be especially insightful in an adjuvant setting. Future research should also implement RCTs in real-world settings, using linkage of electronic health records to administrative databases (Booth et al. 2019). 


\section{MATERIALS AND METHODS}

\section{Data source}

The French national health insurance database (SNDS, Système National des Données de Santé, formerly SNIIRAM, Système national d'information inter-régimes de l'Assurance maladie) covers $98.8 \%$ of the entire population living in France (around 66 million inhabitants) and contains exhaustive data on all reimbursements for health-related expenditures, including dispensed drugs with date of dispensation, as well as individual anonymous data on sociodemographic characteristics (e.g. age, sex, area of residence, date of

death). Information about all hospitalisations in a public or private hospital is also provided: dates of hospital admission and hospital discharge, diagnoses (using ICD-10 codes, international classification of diseases $10^{\text {th }}$ revision) and expensive drugs prescribed during hospital stays. Long-term disease status entitling the patient to full health expenditure coverage, including cancers, is also recorded, with diagnoses encoded according to ICD-10. No biological information is available, notably BRAF mutational status (Bezin et al. 2017; Tuppin et al. 2017).

\section{$\underline{\text { Access authorizations }}$}

The study protocol was approved and authorized in March 2017 by the French Drug Regulatory Agency (ANSM, Agence Nationale de Sécurité du Médicament). Direct access to the SNDS database was granted by ANSM to our research consortium.

\section{Population selection}

We reconstructed a national cohort including every new patient receiving a systemic treatment in France for metastatic melanoma between January 2010 and December 2017. All patients had at least one mention of an ICD-10 code indicating cutaneous melanoma (D03, 


\section{Journal Pre-proo}

C43) and either a mention of chemotherapy (Z51.1 code) or reimbursement for one of the anticancer drugs among the following: vemurafenib, cobimetinib, dabrafenib, trametinib, nivolumab, pembrolizumab, ipilimumab, temozolomide, fotemustine (nota: because of different billing rules, among the classic chemotherapy drugs, the last two could be specifically mentioned, while dacarbazine and other less commonly used drugs came under the Z51.1 code with no specific tracking details). We excluded patients with evidence of another contemporaneous cancer. We excluded patients who had received a systemic treatment for melanoma during the year 2009 , so as to retain only newly-treated metastatic melanoma patients between 2010 and $2017(\mathrm{n}=10,936)$. The detailed selection process is presented in Supplementary Table S4.

\section{Cohort constitution}

The 10,936 patients were divided into 4 successive cohorts, according to when their first treatment line was initiated. Dates for availability (including early access programs) of new drug categories were used to define the cut-offs between cohorts (Figure 1). Thus, cohort 1 included patients for whom a first-line treatment was initiated for metastatic melanoma from January 1, 2010 to December 31, 2011. Cohort 2 included patients starting their first systemic treatment after BRAF inhibitors had been available for $B R A F$-mutated melanomas (i.e. between January 1, 2012 and October 31, 2013). Cohort 3 included patients beginning their first line of treatment just after the approval of ipilimumab as a first-line treatment (i.e. between November 1, 2013 and May 31, 2015). Cohort 4 started with the combination of MEK and BRAF inhibitors for BRAF-mutated melanomas, and anti-PD-1 antibodies, irrespective of BRAF mutational status (i.e. from June 1, 2015 to December 31, 2017). 


\section{$\underline{\text { Treatment lines and care trajectories }}$}

A treatment line was defined as a series of consecutive dispensations of the same drug category. The date of initiation of the treatment line was the date of the first dispensation. The treatment line was considered as discontinued when another treatment line was initiated. If no subsequent treatment was initiated within 3 months after the last recorded dispensation for a given drug category, the treatment line was modelled to end 3 months after the last recorded dispensation. Since ipilimumab is delivered as a fixed series of 4 infusions, patients were considered as receiving it until initiation of subsequent therapy, if any. Otherwise, ipilimumab was modelled to end 3 months after the last infusion. Treatments were defined according to drug categories: targeted therapy, ipilimumab, anti-PD-1 antibodies, combination of ipilimumab and anti-PD-1 antibodies, and chemotherapy. Targeted therapies included BRAF inhibitors (vemurafenib, dabrafenib) and combinations of BRAF and MEK inhibitors (vemurafenib and cobimetinib, dabrafenib and trametinib). Chemotherapy lines included all cytotoxic chemotherapies under the Z51.1 code. Two drugs - temozolomide and fotemustine - were also identified by way of a specific tracking system. A small proportion of Z51.1coded treatment lines could have related to the participation in a clinical trial rather than a sequence of chemotherapy infusions. This is the reason why we labeled the corresponding treatment category as "chemotherapy \& other".

Care trajectories from the first treatment dispensation for metastatic melanoma were analyzed using Sankey diagrams. The status of the patient (which treatment does the patient receive? is he/she still being treated? is he/she dead?) 6 and 12 months after the beginning of the first treatment line was determined. The Sankey diagrams show each cohort separately, with cohort 4 restricted to patients beginning their first-line treatment before December 31, 2016, so that every patient had a minimum of 12 months follow-up. 


\section{Survival analysis}

Survival was estimated from the initiation of the first treatment line to the date of death, or until censoring on December 31, 2017. The 12-month, 24-month and median overall survival were estimated using the Kaplan-Meier method for each of the 4 cohorts. Overall survival was also estimated for the two most commonly prescribed first-line drugs in each cohort. As there was no lost to follow-up, each patient from cohorts 1 to 3 had respectively at least 72, 50 and 310 months of follow-up, except in case of death. Overall survival across the 4 cohorts was first compared using a univariate Cox proportional hazards model. To further take into account potential confounders, age, sex, number and location of metastatic sites, prior surgical resection or radiotherapy, and comorbidities were tested for independence using a multivariate backward stepwise Cox regression analysis. Proportional hazards were assessed by plotting $\log (-\log ($ survival $))$ versus $\log$ of survival time for categorical covariates, and scaled Schönfeld residuals versus survival time for continuous covariates. HR resulting from a follow-up time limited to 31 months for each cohort provided similar results.

Statistical analyses were performed using SAS Enterprise Guide Software (SAS Institute, Inc., USA, version 9.4).

This study followed the REporting of studies Conducted using Observational Routinelycollected health Data (RECORD) guideline. 


\section{DATA ACCESS AND CLEANING METHODS}

The authors (FP, SK, AH, EO and AD) had full access to all the data (extracted from the SNDS database) that was used to generate the study population. The database extracted was stored locally in a dedicated and secure data centre: extraction was performed by CNAMTS; csv data files were imported into the MySql database with a physical data model consistent with the original SNDS database design; the investigators had no direct access to SNDS. Different metrics and visual tools were used to check data completeness and fit to expected data extraction: the metrics included the number of patients extracted (compared to the expected number) and the stability of reimbursement frequencies over time in order to validate data completeness at population level.

\section{DATA AVAILABILITY}

The protocol and the statistical code are is available on justified request. Under French law and regulations, databases extracted from the SNDS cannot be made available.

\section{CONFLICTS OF INTEREST}

Dr Boussemart reports personal fees from BMS, grants and personal fees from Roche, personal fees from Pierre Fabre, grants and personal fees from Novartis, grants from MSD outside the submitted work. Dr Lesimple reports grants from Roche, personal fees from MSD, personal fees from Pierre Fabre, personal fees from Novartis outside the submitted work. Prof Oger reports grants from ANSM (French Health Product Agency) during the conduct of the study. Other authors have nothing to disclose. 


\section{ACKNOWLEDGEMENTS}

We would like to thank Prof Céleste Lebbé and Prof Jean-Jacques Grob for their critical review of an earlier version of the manuscript. We thank Ms Angela Verdier and Ms Sarah Leyshon for the English language revision.

\section{FUNDING}

This work was supported by a grant from the French National Agency for the safety of Medicines and Health Products (Agence Nationale de Sécurité du Médicament - ANSM), France.

\section{ROLE OF THE FUNDING SOURCE}

The funding source revised the protocol and critically appraised the internal study report. The funding source had no role in drafting the manuscript.

\section{AUTHOR CONTRIBUTIONS}

Study concepts: Dr Poizeau, Ms Rault, Prof Oger, Prof Dupuy

Study design: Dr Poizeau, Ms Rault, Dr Tuppin, Prof Guillot, Ms Thuret, Prof Oger, Prof

Dupuy

Data acquisition: Ms Kerbrat, Dr Happe, Mr Balusson

Quality control of data and algorithms: Dr Poizeau, Ms Kerbrat, Dr Happe, Mr Balusson

Data analysis and interpretation: all authors

Statistical analysis: Dr Poizeau

Manuscript preparation: Dr Poizeau, Prof Dupuy

Manuscript editing: all authors

Manuscript review: all authors. 


\section{REFERENCES}

Balch CM, Gershenwald JE, Soong S, Thompson JF, Atkins MB, Byrd DR, et al. Final Version of 2009 AJCC Melanoma Staging and Classification. J. Clin. Oncol. 2009;27(36):6199-206

Bannay A, Chaignot C, Blotière P-O, Basson M, Weill A, Ricordeau P, et al. The Best Use of the Charlson Comorbidity Index With Electronic Health Care Database to Predict Mortality. Med. Care. 2016;54(2):188-94

Bezin J, Duong M, Lassalle R, Droz C, Pariente A, Blin P, et al. The national healthcare system claims databases in France, SNIIRAM and EGB: Powerful tools for pharmacoepidemiology.

Pharmacoepidemiol. Drug Saf. 2017;26(8):954-62

Bocquet-Tremoureux S, Scharbarg E, Nguyen J-M, Varey E, Quereux G, Saint-Jean M, et al. Efficacy and safety of nivolumab in metastatic melanoma: real-world practice. Eur. J. Dermatology.

2019;29(3):315-21

Booth CM, Karim S, Mackillop WJ. Real-world data: towards achieving the achievable in cancer care. Nat. Rev. Clin. Oncol. 2019;16(5):312-25

Bucheit AD, Syklawer E, Jakob JA, Bassett RL, Curry JL, Gershenwald JE, et al. Clinical characteristics and outcomes with specific BRAF and NRAS mutations in patients with metastatic melanoma. Cancer. 2013;119(21):3821-9

Charlson M, Szatrowski TP, Peterson J, Gold J. Validation of a combined comorbidity index. J. Clin. Epidemiol. 1994;47(11):1245-51

Cowey CL, Liu FX, Boyd M, Aguilar KM, Krepler C. Real-world treatment patterns and clinical outcomes among patients with advanced melanoma. Medicine (Baltimore). 2019;98(28):e16328

D'Agostino RB, D'Agostino RB. Estimating Treatment Effects Using Observational Data. JAMA. 2007;297(3):314

Defossez G, Le Guyader-Peyrou S, Uhry Z, Grosclaude P, Colonna M, Dantony E et al. Estimations nationales de l'incidence et de la mortalité par cancer en France métropolitaine entre 1990 et 2018. Volume 1 - Tumeurs solides. [Internet]. Saint-Maurice Santé publique Fr. 2019. [cited 2019 Jan 28]. Available from:

http://www.santepubliquefrance.fr/,https://geodes.santepubliquefrance.fr;http://lesdonnees.e-cancer.fr/ ;https://www.e-cancer.fr/

Donia M, Ellebaek E, Øllegaard TH, Duval L, Aaby JB, Hoejberg L, et al. The real-world impact of modern treatments on the survival of patients with metastatic melanoma. Eur. J. Cancer. 2019;108:2532

Eggermont AMM, Blank CU, Mandala M, Long G V., Atkinson V, Dalle S, et al. Adjuvant Pembrolizumab versus Placebo in Resected Stage III Melanoma. N. Engl. J. Med. 2018;378(19):1789-801

Eggermont AMM, Chiarion-Sileni V, Grob J-J, Dummer R, Wolchok JD, Schmidt H, et al. Prolonged Survival in Stage III Melanoma with Ipilimumab Adjuvant Therapy. N. Engl. J. Med.

2016;375(19):1845-55

Eggermont AMM, Robert C. New drugs in melanoma: It's a whole new world. Eur. J. Cancer. 2011;47(14):2150-7

Elting LS, Cooksley C, Bekele BN, Frumovitz M, Avritscher EBC, Sun C, et al. Generalizability of cancer clinical trial results: Prognostic differences between participants and nonparticipants. Cancer. 2006;106(11):2452-8 
Flaherty KT, Infante JR, Daud A, Gonzalez R, Kefford RF, Sosman J, et al. Combined BRAF and MEK Inhibition in Melanoma with BRAF V600 Mutations. N. Engl. J. Med. 2012;367(18):1694-703

Forschner A, Eichner F, Amaral T, Keim U, Garbe C, Eigentler TK. Improvement of overall survival in stage IV melanoma patients during 2011-2014: analysis of real-world data in 441 patients of the German Central Malignant Melanoma Registry (CMMR). J. Cancer Res. Clin. Oncol. Springer Berlin Heidelberg; 2016;1-8

Fraser J, Steele N, Al Zaman A, Yule A. Are patients in clinical trials representative of the general population? Dose intensity and toxicities associated with FE100C-D chemotherapy in a non-trial population of node positive breast cancer patients compared with PACS-01 trial group. Eur. J. Cancer. Elsevier Ltd; 2011;47(2):215-20

Hauschild A, Dummer R, Schadendorf D, Santinami M, Atkinson V, Mandalà M, et al. Longer Follow-Up Confirms Relapse-Free Survival Benefit With Adjuvant Dabrafenib Plus Trametinib in Patients With Resected BRAF V600-Mutant Stage III Melanoma. J. Clin. Oncol. 2018;36(35):3441-9

INCa. Plateformes hospitalières de génétique moléculaire des cancers : faits marquants et synthèse d'activité 2013. Collection Bilans d'activité et d'évaluation, ouvrage collectif édité par l'INCa, Boulogne-Billancourt, novembre 2014. [Internet]. 2013 [cited 2020 Jan 28]. Available from: https://www.e-cancer.fr/Expertises-et-publications/Catalogue-des-publications/Plateformeshospitalieres-de-genetique-moleculaire-des-cancers-faits-marquants-et-synthese-d-activite-2013

Jochems A, Leeneman B, Franken MG, Schouwenburg MG, Aarts MJB, van Akkooi ACJ, et al. Realworld use, safety, and survival of ipilimumab in metastatic cutaneous melanoma in The Netherlands. Anticancer. Drugs. 2018;29(6):572-8

Jochems A, Schouwenburg MG, Leeneman B, Franken MG, van den Eertwegh AJM, Haanen JBAG, et al. Dutch Melanoma Treatment Registry: Quality assurance in the care of patients with metastatic melanoma in the Netherlands. Eur. J. Cancer. 2017;72:156-65

Kandel M, Allayous C, Dalle S, Mortier L, Dalac S, Dutriaux C, et al. Update of survival and cost of metastatic melanoma with new drugs: Estimations from the MelBase cohort. Eur. J. Cancer.

2018;105:33-40

Larkin J, Ascierto PA, Dréno B, Atkinson V, Liszkay G, Maio M, et al. Combined vemurafenib and cobimetinib in BRAF-mutated melanoma. N. Engl. J. Med. 2014;371(20):1867-76

Long G V., Hauschild A, Santinami M, Atkinson V, Mandalà M, Chiarion-Sileni V, et al. Adjuvant Dabrafenib plus Trametinib in Stage III BRAF-Mutated Melanoma. N. Engl. J. Med. 2017;377(19):1813-23

Long G V, Menzies AM, Nagrial AM, Haydu LE, Hamilton AL, Mann GJ, et al. Prognostic and clinicopathologic associations of oncogenic BRAF in metastatic melanoma. J. Clin. Oncol.

2011;29(10):1239-46

Long G V., Stroyakovskiy D, Gogas H, Levchenko E, de Braud F, Larkin J, et al. Combined BRAF and MEK Inhibition versus BRAF Inhibition Alone in Melanoma. N. Engl. J. Med.

2014;371(20):1877-88

Luke JJ, Ghate SR, Kish J, Lee CH, McAllister L, Mehta S, et al. Targeted agents or immunooncology therapies as first-line therapy for BRAF-mutated metastatic melanoma: a real-world study. Futur. Oncol. 2019;15(25):2933-42

Mangana J, Cheng PF, Kaufmann C, Amann VC, Frauchiger AL, Stögner V, et al. Multicenter, reallife experience with checkpoint inhibitors and targeted therapy agents in advanced melanoma patients in Switzerland. Melanoma Res. 2017;27(4):358-68 
Moser JC, Chen D, Hu-Lieskovan S, Grossmann KF, Patel S, Colonna S V., et al. Real-world survival of patients with advanced BRAF V600 mutated melanoma treated with front-line BRAF/MEK inhibitors, anti-PD-1 antibodies, or nivolumab/ipilimumab. Cancer Med. 2019;8(18):7637-43

Moser JC, Wei G, Colonna S V, Grossmann KF, Patel S, Hyngstrom JR. Comparative-effectiveness of pembrolizumab vs. nivolumab for patients with metastatic melanoma. Acta Oncol; 2020;59(4):434-7

Polkowska M, Ekk-Cierniakowski P, Czepielewska E, Wysoczański W, Matusewicz W, KozłowskaWojciechowska M. Survival of melanoma patients treated with novel drugs: retrospective analysis of real-world data. J. Cancer Res. Clin. Oncol. 2017;143(10):2087-94

Prasad V, Massey PR, Fojo T. Oral Anticancer Drugs: How Limited Dosing Options and Dose Reductions May Affect Outcomes in Comparative Trials and Efficacy in Patients. J. Clin. Oncol. 2014;32(15):1620-9

Robert C, Karaszewska B, Schachter J, Rutkowski P, Mackiewicz A, Stroiakovski D, et al. Improved Overall Survival in Melanoma with Combined Dabrafenib and Trametinib. N. Engl. J. Med. 2015;372(1):30-9

Sanoff HK, Chang Y, Lund JL, O'Neil BH, Dusetzina SB. Sorafenib Effectiveness in Advanced Hepatocellular Carcinoma. Oncologist. 2016;21(9):1113-20

Schilling B, Martens A, Geukes Foppen MH, Gebhardt C, Hassel JC, Rozeman EA, et al. First-line therapy-stratified survival in BRAF-mutant melanoma: a retrospective multicenter analysis. Cancer Immunol. Immunother. 2019;68(5):765-72

Schouwenburg MG, Jochems A, Leeneman B, Franken MG, van den Eertwegh AJM, Haanen JBAG, et al. Vemurafenib in BRAF-mutant metastatic melanoma patients in real-world clinical practice.

Melanoma Res. 2018;28(4):1

Stukel TA, Fisher ES, Wennberg DE, Alter DA, Gottlieb DJ, Vermeulen MJ. Analysis of Observational Studies in the Presence of Treatment Selection Bias. JAMA. 2007;297(3):278

Tarhini A, Atzinger C, Gupte-Singh K, Johnson C, Macahilig C, Rao S. Treatment patterns and outcomes for patients with unresectable stage III and metastatic melanoma in the USA. J. Comp. Eff. Res. 2019;8(7):461-73

Tétu P, Allayous C, Oriano B, Dalle S, Mortier L, Leccia M-T, et al. Impact of radiotherapy administered simultaneously with systemic treatment in patients with melanoma brain metastases within MelBase, a French multicentric prospective cohort. Eur. J. Cancer. 2019;112:38-46

Thomas NE, Edmiston SN, Alexander A, Groben PA, Parrish E, Kricker A, et al. Association Between $N R A S$ and BRAF Mutational Status and Melanoma-Specific Survival Among Patients With HigherRisk Primary Melanoma. JAMA Oncol. 2015;1(3):359

Tuppin P, Rudant J, Constantinou P, Gastaldi-Ménager C, Rachas A, de Roquefeuil L, et al. Value of a national administrative database to guide public decisions: From the système national d'information interrégimes de l'Assurance Maladie (SNIIRAM) to the système national des données de santé (SNDS) in France. Rev. Epidemiol. Sante Publique. 2017;65 Suppl 4:S149-67

Ugurel S, Röhmel J, Ascierto PA, Flaherty KT, Grob JJ, Hauschild A, et al. Survival of patients with advanced metastatic melanoma: the impact of novel therapies-update 2017. Eur. J. Cancer. 2017;83:247-57

Weber J, Mandala M, Del Vecchio M, Gogas HJ, Arance AM, Cowey CL, et al. Adjuvant Nivolumab versus Ipilimumab in Resected Stage III or IV Melanoma. N. Engl. J. Med. 2017;377(19):1824-35

Whitman ED, Liu FX, Cao X, Diede SJ, Haiderali A, Abernethy AP. Treatment patterns and outcomes 
Journal Pre-proof

for patients with advanced melanoma in US oncology clinical practices. Future Oncol. 2019;15(5):459-71 
Table 1. Demographic characteristics of metastatic melanoma patients.

Patients beginning a systemic treatment for metastatic melanoma in France between 2010 and 2017 broken down into 4 successive cohorts, according to the time period in which they began the first-line treatment.

\begin{tabular}{|c|c|c|c|c|}
\hline Characteristics & $\begin{array}{c}\text { Cohort } 1 \\
\text { Jan } 2010-\text { Dec } \\
2011 \\
N=1808\end{array}$ & $\begin{array}{c}\text { Cohort } 2 \\
\text { Jan } 2012-\text { Oct } \\
2013 \\
N=2069\end{array}$ & $\begin{array}{c}\text { Cohort } 3 \\
\text { Nov } 2013-\text { May } \\
2015 \\
N=2334\end{array}$ & $\begin{array}{c}\text { Cohort } 4 \\
\text { Jun } 2015-\text { Dec } \\
2017 \\
N=4725\end{array}$ \\
\hline $\begin{array}{l}\text { Sex, } n(\%) \\
\text { Men } \\
\text { Women }\end{array}$ & $\begin{array}{c}1015(56) \\
793(44)\end{array}$ & $\begin{array}{c}1187(57) \\
882(43)\end{array}$ & $\begin{array}{c}1369(59) \\
965(41)\end{array}$ & $\begin{array}{l}2733(58) \\
1992(42)\end{array}$ \\
\hline $\begin{array}{l}\text { Age, y } \\
\text { Median (IQR) } \\
\text { Mean (sd) } \\
\end{array}$ & $\begin{array}{c}66(54-77) \\
65(15) \\
\end{array}$ & $\begin{array}{l}65(53-76) \\
64(15) \\
\end{array}$ & $\begin{array}{l}67(54-76) \\
65(15) \\
\end{array}$ & $\begin{array}{l}68(54-78) \\
65(15) \\
\end{array}$ \\
\hline $\begin{array}{l}\text { Comorbidities }{ }^{1}, n(\%) \\
\text { Myocardial infarction } \\
\text { Congestive heart failure } \\
\text { Peripheral vascular disease } \\
\text { Cerebrovascular disease } \\
\text { Dementia } \\
\text { Chronic pulmonary disease } \\
\text { Connective tissue disease } \\
\text { Ulcer disease } \\
\text { Mild liver disease } \\
\text { Diabetes } \\
\text { Diabetes with end-organ } \\
\text { damage } \\
\text { Moderate or severe renal } \\
\text { disease } \\
\text { Hemiplegia } \\
\text { Moderate or severe liver } \\
\text { disease } \\
\text { HIV infection } \\
\end{array}$ & $\begin{array}{l}9(0.5) \\
43(2) \\
56(3) \\
75(4) \\
11(1) \\
137(8) \\
24(1.3) \\
14(0.8) \\
35(2) \\
148(8) \\
32(2) \\
50(3) \\
58(3) \\
6(0.3) \\
2(0.1) \\
\end{array}$ & $\begin{array}{l}17(0.8) \\
73(4) \\
71(3) \\
92(5) \\
17(1) \\
175(9) \\
25(1.2) \\
11(0.5) \\
34(2) \\
222(11) \\
36(2) \\
61(3) \\
86(4) \\
3(0.1) \\
6(0.3) \\
\end{array}$ & $\begin{array}{l}22(0.9) \\
66(3) \\
66(3) \\
100(4) \\
15(1) \\
189(8) \\
20(0.9) \\
12(0.5) \\
31(1) \\
259(11) \\
37(2) \\
71(3) \\
92(4) \\
5(0.2) \\
6(0.3) \\
\end{array}$ & $\begin{array}{c}49(1.0) \\
161(3) \\
169(4) \\
237(5) \\
43(1) \\
432(9) \\
62(1.3) \\
21(0.4) \\
71(2) \\
556(12) \\
85(2) \\
171(4) \\
\\
193(4) \\
19(0.4) \\
7(0.2) \\
\end{array}$ \\
\hline $\begin{array}{l}\text { Charlson comorbidity index } \\
\text { Median (IQR) } \\
\text { Mean (sd) }\end{array}$ & $\begin{array}{c}8(8-9) \\
8(1)\end{array}$ & $\begin{array}{c}8(8-9) \\
9(1)\end{array}$ & $\begin{array}{c}8(8-9) \\
9(1)\end{array}$ & $\begin{array}{c}8(8-9) \\
9(1)\end{array}$ \\
\hline $\begin{array}{l}\text { Metastatic sites }{ }^{4}, n(\%) \\
\text { Lymph node } \\
\text { Lung } \\
\text { Liver } \\
\text { Brain } \\
\text { Bone }\end{array}$ & $\begin{array}{l}994(55) \\
881(49) \\
549(30) \\
564(31) \\
380(21)\end{array}$ & $\begin{array}{l}1156(56) \\
957(46) \\
628(30) \\
674(33) \\
427(21)\end{array}$ & $\begin{array}{l}1275(55) \\
982(42) \\
553(24) \\
622(27) \\
409(18)\end{array}$ & $\begin{array}{c}2452(52) \\
1761(37) \\
1063(23) \\
1081(23) \\
837(18)\end{array}$ \\
\hline $\begin{array}{l}\text { Number of metastatic sites }{ }^{4} \\
\text { Mean (sd) }\end{array}$ & $2.9(1.6)$ & $2.8(1.6)$ & $2.6(1.5)$ & $2.5(1.5)$ \\
\hline $\begin{array}{l}\text { Surgical resection }^{5}, n(\%) \\
\text { Lymphadenectomy } \\
\text { Subcutaneous metastases } \\
\text { Distant metastases }\end{array}$ & $\begin{array}{l}412(23) \\
342(19) \\
224(12)\end{array}$ & $\begin{array}{l}594(29) \\
403(20) \\
224(11)\end{array}$ & $\begin{array}{l}713(31) \\
169(20) \\
254(11)\end{array}$ & $\begin{array}{l}1536(33) \\
962(20) \\
514(11) \\
\end{array}$ \\
\hline Radiotherapy $^{5}, n(\%)$ & $132(7)$ & $295(14)$ & $271(12)$ & $507(11)$ \\
\hline
\end{tabular}

${ }^{1}$ recorded over the 12 months before initiation of the first-line treatment, using the algorithm developed by

Bannay et al. for the use of the Charlson comorbidity index with Electronic Health Care database (Bannay et al. 2016)

${ }^{2}$ age-ajusted Charlson index (Bannay et al. 2016; Charlson et al. 1994)

${ }^{3}$ minimum score of 8 because of the cancer ( 2 points) and the metastatic stage ( 6 points)

${ }^{4}$ identified from the hospitalisation discharge codes in the 3 months before and after initiation of the first-line treatment

${ }^{5}$ within the 12 months before initiation of the first-line treatment

${ }^{6}$ mainly including brain, digestive, liver and pulmonary sites 
Journal Pre-proof

Table 2. Comparative overall survival (OS) across the 4 cohorts of metastatic melanoma patients in France.

\begin{tabular}{|c|c|c|c|c|}
\hline Overall survival & $\begin{array}{c}\text { Cohort } 1 \\
\text { Jan } 2010-\text { Dec } \\
2011 \\
N=1808\end{array}$ & $\begin{array}{c}\text { Cohort } 2 \\
\text { Jan } 2012-\text { Oct } \\
2013 \\
N=2069\end{array}$ & $\begin{array}{c}\text { Cohort 3 } \\
\text { Nov } 2013-\text { May } \\
2015 \\
N=2334\end{array}$ & $\begin{array}{c}\text { Cohort } 4 \\
\text { Jun } 2015-\text { Dec } \\
2017 \\
N=4725\end{array}$ \\
\hline $\begin{array}{l}\text { median OS } \\
\text { months }[95 \% \mathrm{CI}]\end{array}$ & $8.5[7.9-9.0]$ & $8.6[7.9-9.1]$ & $12.5[11.4-13.5]$ & $18.0[16.8-19.6]$ \\
\hline $\begin{array}{l}\text { 12-month OS } \\
\%[95 \% \mathrm{CI}]\end{array}$ & $38.7[36.4-40.9]$ & 39.8 [37.7-41.9] & $50.5[48.5-52.5]$ & 59.4 [57.8-60.9] \\
\hline $\begin{array}{l}\text { 24-month OS } \\
\%[95 \% \mathrm{CI}]\end{array}$ & $21.2[19.4-23.1]$ & $23.8[21.9-25.6]$ & $36.0[34.1-38.0]$ & $44.4[42.4-46.3]$ \\
\hline
\end{tabular}

CI: confidence interval. OS: overall survival. 
Figure 1. First-line treatment for metastatic melanoma in France. Evolution over the 20102017 period.

a. Timeline of novel therapy approvals for metastatic melanoma in France. b. Number of patients beginning a first-line treatment for metastatic melanoma, per trimester and per drug, in France. c. Distribution of first-line treatment for metastatic melanoma, per trimester, in France. Segmentation of 4 successive cohorts according to major changes in first-line treatment used.

Anti-PD-1 antibodies include pembrolizumab and nivolumab. Targeted therapies include dabrafenib, vemurafenib, used alone or in combination with trametinib and cobimetinib respectively. Chemotherapy \& other include temozolomide, fotemustine, cytotoxic chemotherapies that are not individually identifiable including dacarbazine, and some nonvisible drug dispensations during clinical trials.

Figure 2. Changes over time in the healthcare trajectory (2010-2017).

Patient status was provided 6 and 12 months after the beginning of the first-line treatment. Each Sankey diagram shows the healthcare trajectory of patients belonging to a cohort (cohorts 1 to 4 respectively on panels a to d). Cohort 4 was limited to patients beginning their first-line treatment between June 2015 and December 2016, so that they have a minimum follow-up of 12 months.

Figure 3. Comparative overall survival across the 4 cohorts of advanced melanoma patients in France (2010-2017).

Kaplan-Meier curves for overall survival are shown per cohort. Cohorts 1 to 4 correspond to patients receiving a first-line systemic treatment for metastatic melanoma between Jan 2010 to Dec 2011, Jan 2012 to Oct 2013, Nov 2013 to May 2015, Jun 2015 to Dec 1017,

respectively. As there was no loss-to-follow-up, all censored patients were individuals who were still alive on December 31, 2017.

Two-year overall survival was computed for each cohort.

Figure 4. Comparative overall survival (OS) for metastatic melanoma patients within cohorts, according to the treatment received as first-line therapy.

Kaplan-Meier curves for overall survival are shown per cohort, for the two most commonly received treatments in each cohort.

a. Cohort 1 (Jan 2010 - Dec 2011). b. Cohort 2 (Jan 2012 - Oct 2013). c. Cohort 3 (Nov 2013

- May 2015). d. Cohort 4 (Jun 2015 - Dec 1017). 


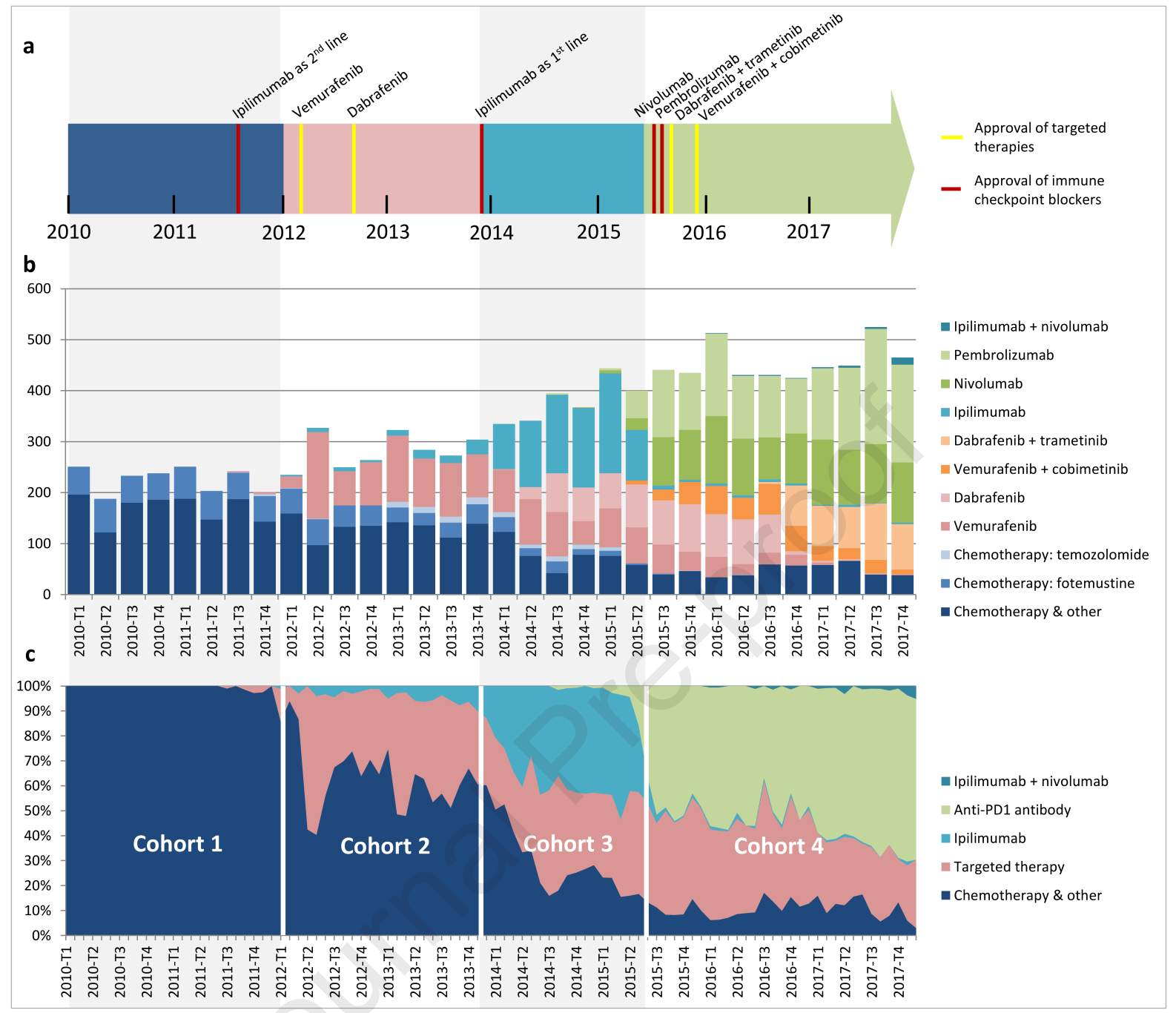




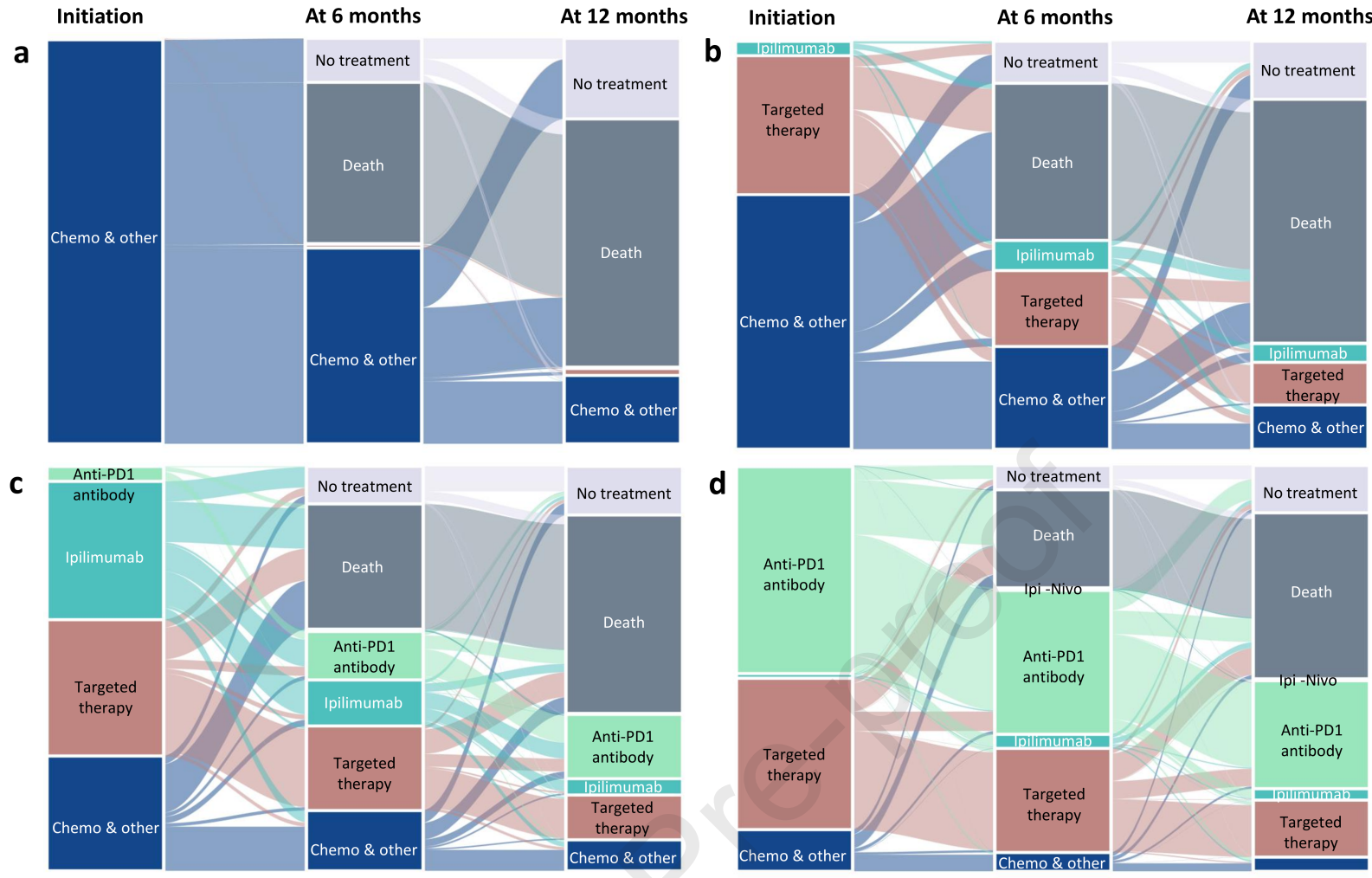

" Chemo \& other " corresponds to Z511 codes (used for chemotherapy). Some patients participating to clinical trials may belong to this category. Ipi-Nivo corresponds to the association of Ipilimumab and Nivolumab. 


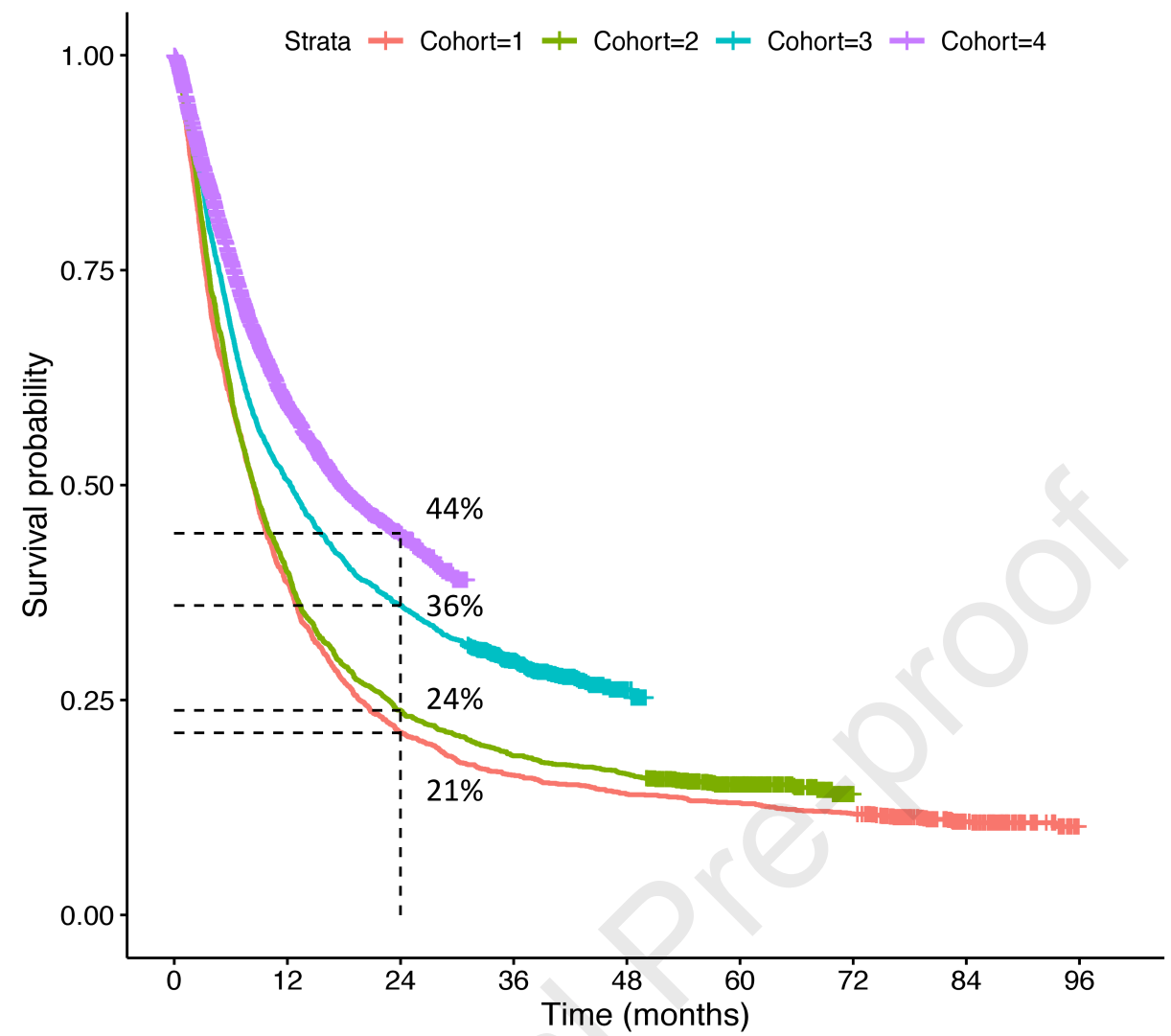

Number at risk

\begin{tabular}{|c|c|c|c|c|c|c|c|c|c|}
\hline Cohort 1 & 1808 & 699 & 384 & 294 & 254 & 236 & 213 & 97 & 0 \\
\hline Cohort 2 & 2069 & 826 & 493 & 383 & 339 & 161 & 1 & 0 & 0 \\
\hline Cohort 3 & 2334 & 1180 & 841 & 455 & 33 & 0 & 0 & 0 & 0 \\
\hline Cohort 4 & 4725 & 1662 & 424 & 0 & 0 & 0 & 0 & 0 & 0 \\
\hline & 0 & 12 & 24 & 36 & 48 & $\begin{array}{l}60 \\
\mathrm{hs})\end{array}$ & 72 & 84 & 96 \\
\hline
\end{tabular}



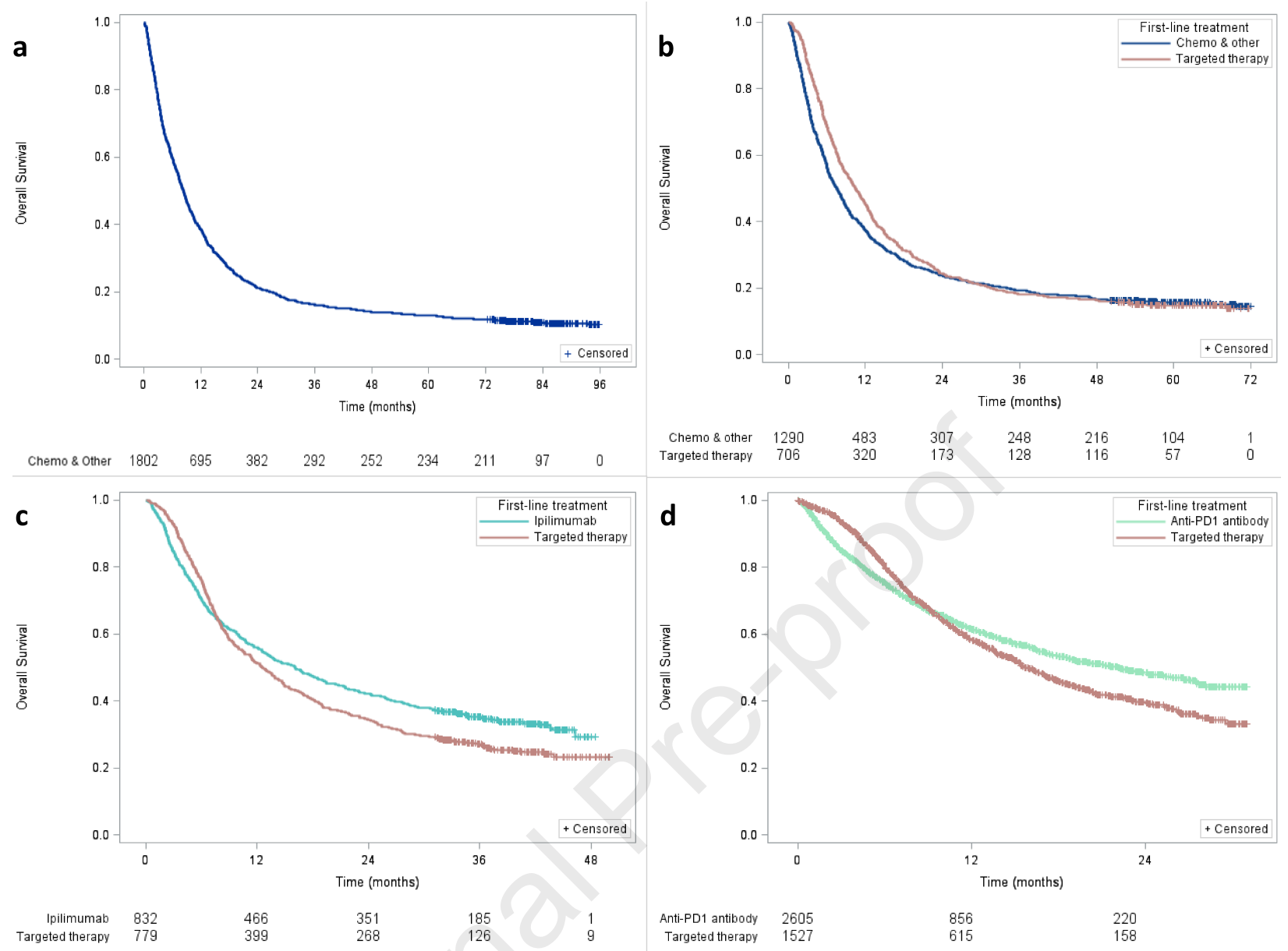